\title{
Using Brunerian Learning Theory with Educational Simulations to Teach Concepts
}

\author{
Laura R. Winer \\ Richard F. Schmid
}

\begin{abstract}
The present study maintains that consistently effective learning materials can best be generated if the prescriptions instructional designers use are founded on learning theory. It is also considered critical that cognitive processes central to the task demands and strategies employed to address them be established. To be practical, we further recommend that only a single, process-oriented lesson, rather than individualized treatment, be implemented. Instructional simulations met these criteria, being tightly bound to Bruner's theoretical approach, and inherently capable of addressing aptitude deficiencies. Subjects were assessed for spatial visualization ability, grouped, randomly assigned to simulation or non-simulation treatments, and tested immediately, one week, and five weeks after instruction. The simulation significantly increased the high-aptitude learners' efficiency (and initially effectiveness), and low-aptitude learners' effectiveness. The validity of a theory-based, aptitude-enhancing, standardized approach was supported, and is discussed.
\end{abstract}

Instructional strategies which consider the ability of students along with the demands of the learning task should result in improved learning. Aptitude $x$ Treatment Interaction (ATI) research calls for just such a match between instruction and learner aptitudes (Cronbach \& Snow, 1977; Wittrock, 1977). Unfortunately, ATI research has not produced a consistent pattern of results (Ausburn \& Ausburn, 1978; Bracht, 1970; Bracht \& Glass, 1968). As Ausbum and Ausbum (1978) and Briggs (1982) pointed out, much of the failure of ATI research to yield practical instructional design principles results from the lack of precision in isolating learner, task, and instruction variables for study and the failure on the part of many researchers to establish a sound rationale for their predictions about interactions. An additional problem with using the ATI paradigm is that the cost of identifying and treating individual learner characterisitics is usually prohibitive. Considered realistically, a single, effective set of instructional materials is usually the most desirable product of the instructional design process. Instructional materials should be tailored to specific task

Laura R. Winer is an Attachée de recherche at APO QUÉBEC, Montreal, Québec. She recently obtained her Ph.D. in Educational Technology at Concordia University. Her current research activities involve applications of computers in education. Richard F. Schmid is an Associate Professor of Educational Technology at Concordia University and Director of Graduate Programs. His research and teaching interests include instructional design, cognitive processes and learning strategies.

CJEC, VOL. 15, NO. 3, PAGES $153-165$, ISSN $0710-4340$ 
demands and should be appropriate to all learners. Any aptitude differences can be addressed by including help for the weaker learners. However, if a single instructional product is to effectively treat all learners, designers must concern themselves as much with the process of learning as with the content.

The most widely utilized learning theory which champions the central position of process over content is that of Jerome Bruner (1964). Bruner maintains that learning is not limited by developmental capabilities, but rather by the quality of and approach to prior learning. His emphasis on the process of learning gives content equal status, but approaches concept acquisition from inside the learner rather than from the teaching end.

Unfortunately educators usually deal with such issues as prior knowledge simply by paying more attention to the entry skills of the learner in order to determine the appropriate content and do even less about learning strategies. Despite over three decades of chiding from Bruner and others that schools must concentrate more on process, little change has occurred. Where process has been the central concern, instruction has lost much of its content, with equally disastrous results. Therefore, a primary objective of this research was to identify and examine an instructional method which is capable of helping all learners by combining content with process under a reliable theoretical framework.

\section{Theory in Instruction: Educational Simulations}

Developing instructional systems by applying a sound psychological theory is not new, it's just unusual. In fact, instructional theory has had very little permanent effect on education. One instructional approach which does rely on theory is educational simulations. Simulations replicate almost precisely the theoretical stipulations of Bruner (Dudley, 1980; Rogers, 1980; Winer \& Vazquez-Abad, 1981). The reasoning is as follows. Bruner's (1964, 1966a, 1966b) model depicts leaming as occurring in three developmental stages - enactive, iconic, and symbolic. This process of learning implies that the learner (whether adult or child) should experience concepts to be learned in a progressive fashion: first in a physical form, then in a pictorial form, and finally at a symbolic level. Bruner also stresses the importance of exploratory learner interaction with concepts and the importance of providing physical models to achieve this. Educational simulations provide these requirements by definition. The developmental and interactive characteristics of simulations place process at the center of the instructional event. Simulations carry the added feature of being largely, though not necessarily, self-instructional. Any self-instructional approach should meet at least three educational needs: (1) the remedial content for weaker students can be efficiently bypassed through branching, (2) the primary content presentation is standardized, thus ensuring the faithful application of the theory, and (3) the problem is amenable to widespread dissemination.

Unfortunately, there has been little empirical support for the use of instructional simulations (Dukes \& Seidner, 1978; Greenblat, 1982; Megarry, 1978; Reiser \& Gerlach, 1977). Reiser and Gerlach cast most of the blame for this on the quality of research that has been done in the area (small samples, inadequate controls, etc.) rather than on the inherent qualities of simulations. Conclusions about simulations are necessarily more tentative because of the variety of events and outcomes possible when using such a dynamic, interactive approach. Finally, Cruickshank and Mager (1976) cited the failure of designers to recognize and follow a theoretical framework for creating simulations as a contributing factor to the conflicting empirical findings. 
Developing educational simulations. To effectively implement the Brunerian learning model, the developmental level of the learners relative to the content must be ascertained. When the content is abstract or symbolic in nature, the designer must carefully weigh the need for either explicitly providing enactive or iconic referents or inducing the learners to provide their own. In a case where a learner's prior knowledge is sufficiently high that the referents are self-evident, the instruction does not have to lead the learner explicitly through the stages. If, however, the learner does not have the capability of generating enactive or iconic representations of the concept, the instruction must either provide them or, preferably, guide the student to discover them via an instructional sequence from concrete to abstract. It is for this type of learner that the ATI paradigm becomes useful. Aptitude relates to processing skills necessary to learn. The designer must identify any cognitive processes involved in the task, and build into the instruction the means for overcoming any deficiencies. Because simulations are self-instructional, capable learners can quickly process or even bypass aptitude enhancement, while less able learners are assisted, thus answering our earlier objection to multiple instructional modes.

Simulation implementation. To test for the viability of employing Brunerian theory in creating an effective simulation, a study was designed whereby explicit enactive, iconic, and symbolic stages were integrated in a controlled instructional sequence. The learner task was to master the principles involved in two and three dimensional factorial designs. The most significant aptitude involved in this task is spatial visualization (Elmore \& Vasu, 1980; Kulhavy, Schmid, \& Dean, 1977). French (1951) and Guilford and Zimmerman (1956) defined spatial visualization as the ability to mentally image movements, transformations, or other changes in three dimensional objects. As spatial visualization is both easy to assess and a potent indicator of success in certain tasks, it was feasible and productive to study the interaction between instructional treatment and spatial visualization ability, again with the intent to create a single product, effective for all learners.

The objective of the simulation was to concretize for students the mental manipulations involved in visualizing factorial designs. The first representation, a physical one, was achieved by having the student build the design with wooden blocks, with each block representing one cell within the design. The second, iconic, was achieved by having students draw the design. The third representational form, symbolic, was involved when learners had to refer to the cells by a system of coordinate notation. The building blocks used in recreating the design operated as a transitional tool which assisted students in making the intellectual leap from a verbal description of a factorial design to its conceptualization in terms of a set of coordinates labeling its component cells. Mayer (1982) described this problem-solving process as having two sub-processes: translation -- understanding the problem by translating it into an internal representation in memory; and solution - applying the rules required to yield an answer. The enactive, and to some extent iconic stages were seen as directly addressing and assisting the translation process, while the interactivity and representation of component relations were viewed as enhancing the acquisition and retention of solution procedures.

This study thus attempted to integrate several areas of inquiry that seem to be logically related. Brunerian theory provides a theoretical rationale for both the design of simulations and the teaching of abstract concepts. Simulations, in turn, offer an instructional approach which is self-contained and therefore somewhat standardized, thus increasing the likelihood of effectiveness. Finally, because Brunerian theory addresses processing factors as central to 
concept acquisition, an aptitude was identified and investigated. The design included standard (control) and simulation groups. Within each were high, medium, and low spatial ability learners. It was expected that there would be an interaction between spatial ability and instructional treatment, with low ability students benefiting from the applied Brunerian treatment and high ability students performing equally well under both treatments.

\section{METHOD}

\section{Design and Subjects}

Two factors, spatial visualization ability and instructional strategy, were isolated in this study. Three levels of spatial ability were determined by subjects' scores on two standardized tests. Instructional strategies employed either a standard textbook method or a Brunerian developmental method (simulation). An immediate posttest and delayed posttest were administered. The design was thus a 3 Spatial Ability (high, medium, and low) $x 2$ Instructional Strategy (standard vs. simulation) x 2 Test Position (immediate and delayed posttests) mixed model. A pretest was also administered to establish group equivalence, and a long-term delayed posttest given.

Subjects were 40 male and female graduate students in an introductory social sciences statistics course. Six subjects were subsequently eliminated for failure to follow procedures.

\section{Materials}

Two tests were used to rank subjects on their spatial visualization ability. The Spatial Visualization Test of the Dailey Vocational Tests (1965) measures the ability to visualize objects presented two dimensionally in three dimensions. The items require the subjects to match the edges of a folded and unfolded figure. Part VI of the Guilford-Zimmerman Aptitude Survey (1956) consists of a series of mental rotations of clocks according to arrows indicating the direction and amount of rotation required. The subject must recognize the final position of the clock from five alternatives.

Two instructional treatments were employed. The standard textbook method was taken almost entirely from Chapter Two of Drew's Introduction to Designing Research and Evaluation (1976). The textbook material was presented in print form, and provided definitions of terms and a discussion of how to represent two and three factor research designs. Minor modifications were made to ensure that it was compatible with the self-study format. The embedded questions, described below, appeared throughout the material, but without the simulation.

The second strategy also made use of the printed textbook material. The difference was that the embedded questions constituted a tutorial/simulation (Wagner, 1982) based on Brunerian learning theory. The simulation was made up of 16 two-and three-way research design problems. The subjects were required to construct the factorial design using wooden building blocks. This entailed the enactive stage. For the iconic stage, students were required to draw the design using the blocks as the model. The symbolic stage required learners to assign a notational label to each cell, using alphabetic symbols for factors, and numbers for levels. Finally, students answered three questions about various aspects of each design (e.g., number of between and within factors, number of different groups required, etc.). These questions were also embedded in the standard materials. 
The pretest and posttests each consisted of five design descriptions and questions similar to those covered in the instructional materials. Subjects were asked to sketch out the design and answer the questions. To generate the tests, a pool of one, two and three factor designs was created, from which the pretest and immediate posttest questions were randomly selected. Thus, two parallel forms were used. The delayed posttest consisted of randomly ordered items used in the pretest.

Finally, the five-week delayed posttest was a regularly scheduled course exam which included three randomly selected items from the above pool, constituting $50 \%$ of the exam. The remaining multiple-choice, short answer, and essay design problems all dealt with the same general content.

\section{Procedure}

The spatial visualization tests were administered in the first class period of the fall term. Counterbalancing was employed by randomly dividing students into two groups, having them write in separate classrooms, and giving one group the Dailey test first and the other the Guilford-Zimmerman first. A Pearson product-moment correlation coefficient was calculated between the scores on the Dailey and Guilford-Zimmerman tests to assess the degree to which these tests measure the same construct. A score of .65 was obtained, statistically significant at the .01 level. Both tests purport to measure the same theoretical construct (Dailey, 1965; Guilford \& Zimmerman, 1956), and this statistic provided further support for this assumption. The scores from the two tests were added and learners were evenly divided into high, medium, and low spatial ability groups based on their total scores. Subjects from these three groups were then randomly assigned to one of two groups of equal size: one received the standard textbook materials only, and the other received the simulation materials.

The pretest, which took 20 minutes, was also administered during the first class following the spatial visualization tests under the guise of general information gathering for the course. Students were told that two instructional methods had been developed for covering the initial course material. As a demonstration of how research is conducted, they would be divided up into two groups, and attend a study session scheduled during the first week (a weekly lab was part of the regular course). They were assured that all materials would eventually be provided for both groups, and while they would not be graded for performance, this study session would provide them with individualized exposure to actual course content. Participation, however, was voluntary.

Subjects were run individually, using the materials in a quiet, well-lit room containing carrells for individual study. All subjects were allowed as much time as they wanted, but a record was kept of the time spent with the instructional materials. The experimenter met them, gave them the materials appropriate for their condition, and left the room. Although materials were completely self-instructional, the experimenter was always available to answer procedural questions. After the subjects had finished going through the materials, they were given 20 minutes to complete the immediate posttest.

The delayed posttest was administered at the beginning of the second class period with students again allowed 20 minutes to complete it. A questionnaire regarding subjects' own perceptions of their spatial ability and their attitudes toward the material they used was then administered. After the delayed posttests and questionnaires had been collected, subjects were given their own scores and group statistics on both spatial tests. 


\section{RESULTS}

The first set of analyses examined the possible order effects of the spatial visualization tests, and the equivalence of groups with respect to prior knowledge as measured by the pretest.

Independent $t$-tests on the raw scores of the two groups of each spatial visualization test produced no significant differences. Counterbalancing therefore proved effective.

The pretests were scored assigning one point per correct answer, with a possible total of 15 . Group equivalence was assessed via a two-way analysis of variance on raw scores. The results were statistically non-significant, and it was thus assumed that the influence of prior knowledge was equally distributed among the groups.

Possible group differences regarding study time on the instructional materials were also analyzed using an ANOVA, and no differences were found. The mean time spent studying was 113 minutes.

\section{Achievement Tests}

As with the pretest, the immediate posttest and delayed posttest were scored awarding one point per correct response, with fifteen points possible. Even though the two tests were considered parallel forms, item difficulty may have varied. Therefore, multivariate procedures were employed as a conservative test of effects.

Raw scores. Means and standard deviations for the two tests are provided in Table 1.

\section{TABLE 1}

\section{Means and Standard Deviations of the Raw Scores}

\begin{tabular}{|c|c|c|c|c|c|}
\hline \multirow[b]{3}{*}{$\begin{array}{l}\text { Test } \\
\text { Position }\end{array}$} & \multirow[b]{3}{*}{$\begin{array}{l}\text { Level of } \\
\text { Spatial Ability }\end{array}$} & \multicolumn{4}{|c|}{ Instructional Treatment } \\
\hline & & \multicolumn{2}{|c|}{ Simulation } & \multicolumn{2}{|c|}{ Standard } \\
\hline & & $M$ & $S D$ & $M$ & $S D$ \\
\hline \multirow{4}{*}{$\begin{array}{l}\text { Immediate } \\
\text { Posttest }\end{array}$} & High & 11.1 & 3.4 & 3.6 & 1.7 \\
\hline & Medium & 6.3 & 1.7 & 5.3 & 2.4 \\
\hline & Low & 4.4 & 3.3 & 2.9 & 2.5 \\
\hline & High & 10.0 & 3.0 & 7.6 & 2.2 \\
\hline \multirow{2}{*}{$\begin{array}{l}\text { Delayed } \\
\text { Posttest }\end{array}$} & Medium & 8.8 & 2.1 & 7.3 & 2.2 \\
\hline & Low & 8.5 & 2.2 & 5.6 & 1.8 \\
\hline
\end{tabular}

A multiple variate analysis of variance was completed on Spatial Ability and Instructional Strategies factors on the raw scores of both the immediate and delayed posttests. The interac- 
tion reached statistical significance, $F(4,54)=3.53, p<.01$. Only the immediate posttest univariate was significant, $F(2,28)=5.22, p<.01$. Figure 1 represents the interaction.

Figure 1.

Mean Raw Scores as a Function of Instructional Treatment and Spatial Ability.

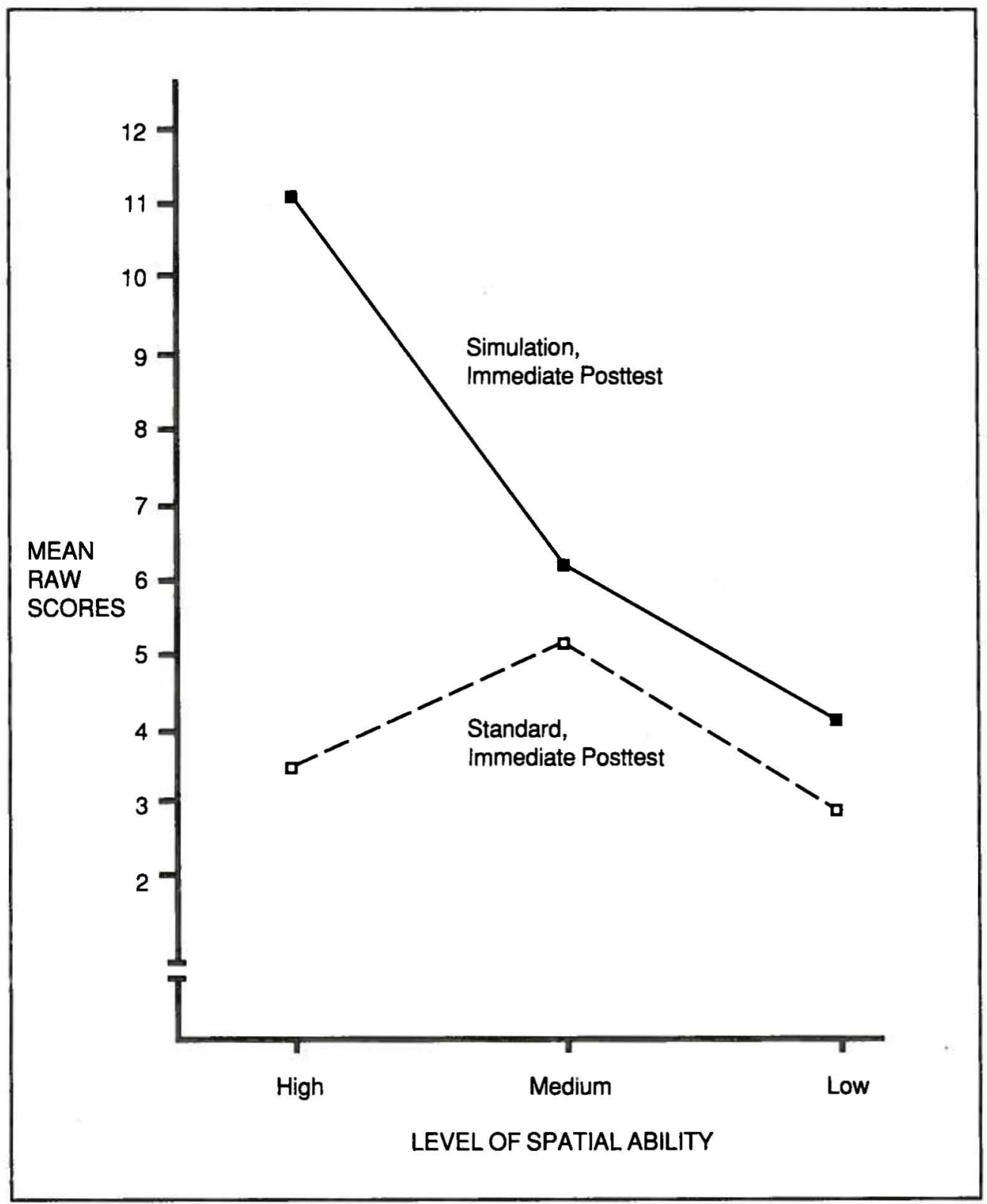


Post hoc analyses were conducted on the interaction. The simple effects comparison confirmed the significant interaction, $F(2.28)=9.54, p<.001$. Individual comparisons showed that while the spatial visualizers' performance differed in the simulation group, they did not in the standard group, with the high outperforming the low group, $F(1,10)=10.56$, $p<.01$. The high visual ability simulation group scored better than all three standard groups, all $p$ 's $<.025$, and the medium visualizers outperformed the high and low visualizers in the standard group, both $p$ 's $<.05$.

Number of problems attempted. Subjects were given a 20-minute time limit for completion of each achievement test, yet it appeared that the learners from different groups had attempted a significantly different number of problems. Table 2 lists the means and standard deviations. An analysis of variance was therefore computed on the immediate and

TABLE 2

Means and Standard Deviations of Number of Problems Attempted

\begin{tabular}{|c|c|c|c|c|c|}
\hline \multirow{3}{*}{$\begin{array}{l}\text { Test } \\
\text { Position }\end{array}$} & \multirow{3}{*}{$\begin{array}{l}\text { Level of } \\
\text { Spatial Ability }\end{array}$} & \multicolumn{4}{|c|}{ Instructional Treatment } \\
\hline & & \multicolumn{2}{|c|}{ Simulation } & \multicolumn{2}{|c|}{ Standard } \\
\hline & & $M$ & $S D$ & $M$ & $S D$ \\
\hline \multirow{3}{*}{ Pretest } & High & 4.6 & .9 & 4.4 & .9 \\
\hline & Medium & 4.3 & .8 & 4.7 & .5 \\
\hline & Low & 4.3 & .8 & 4.0 & .6 \\
\hline \multirow{3}{*}{$\begin{array}{l}\text { Immediate } \\
\text { Posttest }\end{array}$} & High & 4.2 & .8 & 2.8 & .5 \\
\hline & Medium & 3.7 & 1.2 & 3.1 & 1.0 \\
\hline & Low & 2.5 & 1.2 & 3.5 & .8 \\
\hline \multirow{3}{*}{$\begin{array}{l}\text { Delayed } \\
\text { Posttest }\end{array}$} & High & 5.0 & .0 & 4.4 & .9 \\
\hline & Medium & 4.8 & .4 & 4.3 & .8 \\
\hline & Low & 4.0 & .6 & 4.0 & .9 \\
\hline
\end{tabular}

one-week delay posttests. A significant three-way interaction was reached, $F(4,56)=2.72$, $p<.04$. All visualization levels in both treatment groups attempted approximately the same number of problems on the pretest, and delayed posttest, with all means being four or greater. However, individual comparisons of the immediate posttest simulation group showed that low visualizers attempted fewer problems than medium visualizers, who attempted fewer than high visualizers, (all $p<.05$ ). The standard instructional treatment, 
however, reacted in reverse, with the high ability group attempting fewer problems than the low group, both of which did not differ from the medium group (both $p<.05$ ).

\section{Long Term Effect and Attitude Questionnaire}

Because the content overlap on the two sections of the five-week posttest was extremely high, a correlation was calculated on the three questions and the remaining portion, yielding an $r=.91$. Analyses were therefore completed on the total test score to increase reliability and external validity. Test performance was scored by number correct, with a total of fifty points possible.

The means and standard deviations from this exam can be seen in Table 3.

TABLE 3

Means and Standard Deviations of the Delayed Posttest

\begin{tabular}{lcccc}
\hline & \multicolumn{4}{c}{ Instructional Treatment } \\
\cline { 2 - 5 } $\begin{array}{l}\text { Level of } \\
\text { Spatial Ability }\end{array}$ & $M$ & $S D$ & $M$ & $S D$ \\
\hline High & 40.0 & 9.1 & 41.2 & 6.7 \\
Medium & 39.1 & 2.7 & 31.9 & 7.1 \\
Low & 41.2 & 4.2 & 33.5 & 8.1 \\
\hline
\end{tabular}

The ANOVA yielded a significant main effect for treatment $(F(1,25)=4.29, p<.05)$. The large quantitative differences among group means also suggested a trend toward the hypothesized interaction between spatial visualization and treatment, even though the interaction was not statistically significant. (The small number of subjects per cell and increased variance were likely the major factors in the non-significance of this interaction.) While the simulation and standard groups did not differ among the high visualizers, the Brunerian approach made a significant impact on both the medium and low groups, with the standard groups performing less well. The differences are particularly impressive when one notes that the low and medium simulation groups performed almost $25 \%$ better than their standard instruction counterparts.

The attitude questionnaire produced several interesting results. Despite the additional tasks involved, the simulation group rated their treatment significantly easier than the standard group. They also highly recommended the simulation for others ( $M=4$ out of 5 ). On the negative side, they did not feel that the blocks were useful $(M=2)$.

\section{DISCUSSION}

The results supported the hypothesis that simulations which provide a Brunerian-type of conceptual development can be effective. Previous studies on simulations have often 
failed to use a firm theoretical framework when creating materials, and have thus been inconsistent in the strategy being tested. The learning process tested here developed the concepts from the learner's general level of concrete prior knowledge toward a symbolic representation. The strategy's success therefore supports both the effectiveness of Bruner's theoretical framework and a simulation's ability to implement it.

The hypothesis regarding learner aptitude interacting with instructional method was also partially supported, but in an unexpected way. Although we originally assumed that the high spatial ability learners would not need the learning strategy provided by the simulation, they immediately responded in a positive fashion. The concepts' concrete representations appeared to have activated the appropriate prior knowledge structures so that learning was rapid and effective, thus enabling them to outperform their standard counterparts. Only after the five-week delay was the high ability standard group able to again perform as well as the simulation group. The influence of the aptitude finally asserted itself over time, but the distinctive effect of the strategy as opposed to ability were clearly demonstrated. These results correspond to the work of Winn (1982) which emphasizes the importance of ensuring that the specific learning strategy is accessible to the learner. Possessing the ability to employ a cognitive process is insufficient for effective or efficient leaming.

The low spatial group performance conformed to an almost classic ATI formation. Initial reception of the instructional techniques was characteristically slow. However, over the one-week delay period, learners receiving the Brunerian simulation outperformed the standard group as the conceptual organization took effect. The differences remained over the five week delay.

As is often the case in ATI research, the middle ability group contributed results which initially produced no information, but they eventually conformed to the overall pattern. During immediate and delayed tests, they did not respond differentially to the instructional methods, but performed well under both. However, by the five week delay, some differences had emerged between the simulation. Taken together, aptitude did appear to interact somewhat with method.

Problem-solving strategies. With at least partial confirmation of the initial hypotheses complete, additional information was sought regarding group differences. As reported in the Results section, the various between-subject groups differed significantly with respect to the number of problems attempted on the immediate posttest. This suggested to us that different solution strategies were being employed. For example, the high ability simulation group tended to answer all three questions from each problem, and because they understood the content, worked through all five problems and scored well. The control group also attempted to solve all the questions from each problem, but encountered major difficulties with certain questions. Thus, they scored poorly because they spent so much time attempting the difficult questions and only reached two or three of the five. Interestingly, the low ability simulation and non-simulation groups responded in the reverse fashion, i.e., the standard group addressed more problems than the simulation group. It was clear, however,that they attempted more problems in order to answer the easier questions. Their strategy still failed to produce better scores than that of the more deliberate simulation group, apparently because they did not understand the content well enough. The medium groups did not differ.

These results seemed to reflect an interaction between each group's level of confidence of their understanding and their actual level of mastery of the overall content. Logically, these effects were most pronounced during the immediate posttest because all subjects felt 
the most confident and knowledgeable after just having studied the content for a long period. All learners spent more time seriously trying to solve entire problems, and thus generally attempted significantly fewer. Notably, confidence and actual mastery did not correlate well across groups. The high ability group was most confident (and most capable), and performed well. Their standard counterparts did not understand the content nearly as well, yet felt compelled to answer all of each problem's questions, and thus approached as few problems as the low spatial group. With the low ability groups, the simulation students understood enough (or thought they did) to challenge themselves with all the questions of each problem, leading to only a few attempted problems, but they still obtained higher scores than the standard group. It is likely that these different, and sometimes detrimental, strategies led to the significant, anomalous underperformance of the high ability standard group.

Prescriptive conclusions. To simply have demonstrated that simulations are more effective instructional techniques than an alternative method would leave too much in question regarding the techniques employed. To further test the approach, the aptitude which interacts with the content was included with the hope that the simulation's strategy could overcome aptitude deficiencies. The strategy appeared to have accomplished this. Thus, this type of ATI design served two important functions. First, it reiterated the fact that certain tasks call for certain skills, and that instruction might benefit from addressing those skills. Second, it provided a secondary means of assessing whether it was in fact the simulation's strategy which made the difference.

How one knows if instruction is good continues to be a major problem - a question only answerable in a theoretical or post hoc fashion. However, if designers use simulations, employing the principles of Brunerian learning, the likelihood, a priori, of good instruction is increased. To the extent that effective simulations are self-instructional, their quality is further assured. If instructional theory is ever to have an impact on practice, the need for consistent implementation is paramount. Simulations have proved to be highly motivating, allow for individual learning styles (pace, content, and process), and encourage creativity within structure. Designers should also realize that the computer is not necessary for the effective use of simulations (Clark, 1985), as demonstrated here.

The initial contention that a single instructional approach can effectively address all learners found important empirical support. All simulation groups clearly benefited from the nature of the instruction, differing only with respect to when. By using this approach, highability learners could accelerate their program of study due to their immediate receptiveness to the cues of strategy provided, while lower ability learners, given time, could perform at the same high standard as those more able. Learners lacking in prerequisite abilities could be helped directly by the mainstream instructional process rather than within the context of separate remediation.

In summary, the results of this study suggest that educators should recognize relevant aptitudes, provide all learners with the benefits of theoretically based instruction, and for practical purposes deliver materials in a somewhat standardized fashion, an approach similar to Mayer's (1982) compensatory model. It is clear that further examination of other tasks and their respective aptitudes is necessary to confidently generalize these prescriptions. As Sherlock Holmes (in Doyle, 1904) said, "It is a capital mistake to theorize in advance of the facts." Nevertheless, application built on theory appears to hold a great promise for the science of instruction. 


\section{REFERENCES}

Ausburn, L. J., \& Ausburn, F. B (1978). Cognitive styles: Some information and implications for instructional design. Educational Communications and Technology Journal, 26, 337-354.

Bracht, G. H. (1970). The relationship of treatment tasks, personological variables and dependent variables to aptitude-treatment interactions. Review' of Educational Research, 40, 627-674.

Bracht, G. H., \& Glass, G. V. (1968). External validity for experiments. American Educational Research Journal, 5, 437-474.

Briggs, L. J. (1982). Instructional design: Present strengths and limitations, and a view of the future. Educational Technology, 12, 18-23.

Bruner, J. S. (1964). The course of cognitive growth. American Psychologist, 19, 1-15.

Bruner, J. S. (1966a). Studies in cognitive growth. New York: John Wiley \& Sons.

Bruner, J. S. (1966b). Toward a theory of instruction. New York: W. W. Norton \& Company.

Clark, R. E. (1985). Confounding in educational computing research. Journal of Educational Computing Research, 1 (2), 129-140.

Cronbach, L. J., \& Snow, R. E. (1977). Aptitudes and instructional methods. A handbook for research on interactions. New York: Irvington Publishers.

Cruickshank, D. R., \& Mager, G. M. (1976). Toward theory building in the field of instructional games and simulations. Programmed Learning and Educational Technology, 13, 5-9.

Dailey, J. T. (1965). Spatial visualization test of the Dailey vocational tests. Boston: Houghton Mifflin Co.

Doyle, A. C. (Ed.) (1967). The adventure of the second stain. London: The Strand Magazine, 1904. Reprinted in W. S. Baring-Gould (Ed.) The annotated Sherlock Holmes. New York: Clarkson N. Potter, Inc.

Drew, C. J. (1976). Introduction to designing research and evaluation. St. Louis, MO: The C.V. Mosby Company.

Dudley, J. (1980). Discovery learning in simulation/gaming. Simulation/Games for Learning, 10, 123-132.

Dukes, R. L., \& Seidner, C. J. (Eds.) (1978). Learning with simulations and games. Beveriey Hills, CA: Sage Publications.

Elmore, P. B., \& Vasu, E. S. (1980). Relationship between selected variables and statistics achievement: Building a theoretical model. Journal of Educational Psychology, 72, 457-467.

French, J. W. (1951). The description of aptitude and achievement tests in terms of rotated factors. Psychometric Monographs (No. 5). Chicago, IL: University of Chicago Press.

Greenblat, C. S. (1982). Games and simulations. Encyclopedia of Educational Research (5th ed.). New York: The Free Press, 713-716.

Guilford, J. P., \& Zimmerman, W. S. (1956). Guilford-Zimmerman aptitude survey, part VI spatial visualization. Beverley Hills, CA: Sheridan Supply Company. 
Kulhavy, R. W., Schmid, R. F., \& Dean, R. S. (1977). Assessing instrument sensitivity for heading and attitude information. Brooks AFB, TX: Air Force Systems Command.

Mayer, R. E. (1982). Memory for algebra story problems. Journal of Educational Psychology, 74, 199-216.

Megarry, J. (1978). Simulations and games: An introduction. Glasgow, Scotland: Jordonhill College of Education.

Reiser, R. A., \& Gerlach, V. S. (1977). Research on simulation games in education: A critical analysis. Educational Technology, 17, 13-18.

Rogers, P. (1980). Some games with primary school children: An application of Bruner's theory. Simulation/Games for Learning, 10, 107-122.

Wager, W. (1982). Design considerations for instructional computing programs. Journal of Educational Technology Systems, 10, 261-269.

Winer, L. R., \& Vazquez-Abad, J. (1981). Towards a theoretical framework for educational simulations. Simulations/Games for Learning, 11, 114-119.

Winn, W. (1982). Visualization in learning and instruction: A cognitive approach. Educational Communications and Technology Journal, 30, 2-25.

Wittrock, M. C. (Ed.). (1977). Learning and instruction. Berkeley, CA: McCutchan Publishing Corp. 